\title{
Observations of deep-sea fishes and mobile scavengers from the abyssal DISCOL experimental mining area
}

\author{
Jeffrey C. Drazen ${ }^{1}$, Astrid B. Leitner ${ }^{1}$, Sage Morningstar ${ }^{1}$, Yann Marcon ${ }^{2,3}$, Jens Greinert ${ }^{4}$, and Autun Purser ${ }^{2}$ \\ ${ }^{1}$ Department of Oceanography, University of Hawaii, 1000 Pope Rd, Honolulu, HI 96821, USA \\ ${ }^{2}$ Alfred Wegener Institute, Helmholtz Centre for Polar and Marine Research, Am Handelshafen 12, \\ 27570 Bremerhaven, Germany \\ ${ }^{3}$ MARUM Center for Marine Environmental Sciences and Department of Geosciences, University of Bremen, \\ 28359 Bremen, Germany \\ ${ }^{4}$ GEOMAR, Helmholtz Centre for Ocean Research, Wischhofstrasse 1-3, 24148 Kiel, Germany
}

Correspondence: Jeffrey C. Drazen (jdrazen@hawaii.edu)

Received: 7 February 2019 - Discussion started: 20 February 2019

Revised: 16 July 2019 - Accepted: 27 July 2019 - Published: 21 August 2019

\begin{abstract}
Industrial interest in deep-sea mineral extraction began decades ago, and today it is at an all-time high, accelerated by global demand for metals. Several seafloor ecosystem disturbance experiments began in the 1970s, including the Disturbance and Recolonization experiment (DISCOL) conducted in the Peru Basin in 1989. A large seafloor disturbance was created by repeatedly ploughing the seafloor over an area of $\sim 10.8 \mathrm{~km}^{2}$. Though a number of studies in abyssal mining regions have evaluated megafaunal biodiversity and ecosystem responses, few have included quantitative and detailed data on fishes or scavengers despite their ecological importance as top predators. We used towed camera transects (1989-1996, 2015) and baited camera data (19891992) to evaluate the fish community at the DISCOL site. The abyssal fish community included 16 taxa and was dominated by Ipnops meadi. Fish density was lower in ploughed habitat at 6 months and 3 years following disturbance but thereafter increased over time. Twenty-six years after disturbance there were no differences in overall total fish densities between reference and experimental areas, but the dominant fish, I. meadi, still exhibited much lower densities in ploughed habitat, likely avoiding these areas and suggesting that the fish community remains affected after decades. At the scale of industrial mining, these results could translate to population-level effects. The scavenging community was dominated by eelpouts (Pachycara spp.), hermit crabs (Probeebei mirabilis) and shrimp. The large contribution of hermit crabs appears to be unique amongst abyssal scavenger
\end{abstract}

studies worldwide. The abyssal fish community at DISCOL was similar to that in the more northerly Clarion-Clipperton Zone (CCZ), though some species have only been observed at DISCOL thus far. Also, further species-level identifications are required to refine this assessment. Additional studies across the polymetallic nodule provinces of the Pacific are required to further evaluate the environmental drivers of fish density, diversity and species biogeographies. This information will be important for the development of appropriate management plans aimed at minimizing human impact from deep-sea mining.

\section{Introduction}

The world's oceans are becoming increasingly exploited for their resources, and anthropogenic effects now reach the farthest corners and depths of ocean ecosystems (RamirezLlodra et al., 2011). New uses of our oceans are emerging. Industrial interest in deep-sea mineral extraction is at an all-time high, accelerated by global demand for minerals such as cobalt, zinc, copper, nickel and rare-earth elements, which are enriched in seamount crusts as well as manganese nodules and deposited at hydrothermal vents. Currently, the International Seabed Authority has granted 29 exploration contracts to companies to explore for metals and rare-earth minerals in areas totaling $>1200000 \mathrm{~km}^{2}$ of seafloor in the Pacific, Atlantic and Indian oceans (https://www.isa.org.jm, 
last access: 8 April 2019. Though the current intensity of commercial interest combined with technological innovations will soon lead to exploitation, this idea has a long history. Thus several seafloor ecosystem disturbance experiments were performed beginning in the 1970s (reviewed in Jones et al., 2017).

One of these, the Disturbance and Recolonization experiment (DISCOL) was conducted in the Peru Basin in 1989. A large experimental seafloor disturbance was created by repeatedly ploughing the seafloor. Biological surveys were conducted prior to the disturbance and several times thereafter to monitor seafloor ecosystem recovery (Thiel et al., 2001). Studies of the site 7 years after disturbance showed only partial recovery (Thiel et al., 2001; Bluhm, 2001). Similar studies carried out in the North Pacific have also given indications that seafloor communities have not recovered or only partially recovered in periods of 26-37 years following disturbance (Miljutin et al., 2011; Jones et al., 2017; Gollner et al., 2017). This is not surprising given low rates of recruitment and growth common in these ecosystems and the removal of the hard substrate that a large portion of the fauna depends on (Amon et al., 2016; Vanreusel et al., 2016; Purser et al., 2017).

Though a number of studies in abyssal mining regions have evaluated megafaunal biodiversity and ecosystem responses, few have included quantitative and detailed data on fishes or scavengers (Leitner et al., 2017). However, many fishes are top predators that can have important influences on communities and ecosystems (Estes et al., 2011; Drazen and Sutton, 2017). Though fishes are mobile and may not suffer immediate mortality from mining, they will be affected by the large sediment plumes created (Oebius et al., 2001) and by the loss of foraging habitat or prey resources. Thus, they may suffer regionally from local mining activities. Also, top predators can bioaccumulate metals and other contaminants (Chouvelon et al., 2012; Choy et al., 2009; Bonito et al., 2016) that may be released from the activities of mining. Thus, it is important to characterize the fish community in regions that will likely experience mining in the near future and to begin constructing species ranges and community biogeographies so that scientists and managers can evaluate potential mining impacts and appropriately locate protected no-mining zones (Wedding et al., 2013).

In 2015 a survey was performed of the DISCOL area using photo- and video-transecting techniques in a similar manner to the historical surveys of the area conducted into the late 1990s. In addition, archived analogue baited camera images collected shortly after the 1989 disturbance (19891992) were digitized and analyzed for fishes and other mobile scavengers, some of which may avoid transecting vehicles (Trenkel et al., 2004; Colton and Swearer, 2010). Our goal was to (a) describe the fish and scavenger community in the DISCOL region in detail for the first time, (b) evaluate the fish community response to disturbance and potential recovery, and (c) compare the fish and scavenger community to that observed to the north of the Equator in the ClarionClipperton Zone (CCZ). The majority of abyssal mining exploration licenses have been thus far granted in the CCZ, and this is where initial pilot mining activities are likely to commence.

\section{Methods}

In $1989 \mathrm{a} \sim 10.8 \mathrm{~km}^{2}$ circular region of the Peru Basin in the Pacific, the DISCOL experimental area (the DEA), was artificially ploughed in an effort to simulate the effects of deepsea mining (Thiel et al., 2001). The study site $\left(7^{\circ} 04.4^{\prime} \mathrm{S}\right.$, $88^{\circ} 27.60^{\prime} \mathrm{W}$ ) ranges in depth from 4120 to $4200 \mathrm{~m}$. Sediments are fine-grained clays overlain with heterogeneous cover of manganese nodules, sometimes in high density. The plough-harrow device was $8 \mathrm{~m}$ wide and, when deployed, overturned the first $10-15 \mathrm{~cm}$ of seafloor sediment, ploughing the nodules into the seafloor and removing this hard substrate from the sediment-water interface. The plough was towed in 78 radial transects through the disturbance area with $\sim 20 \%$ of the seafloor directly disturbed by the plough. The most central region of the DEA was the most highly disturbed area crosscut by the majority of plough tows (Fig. 1; Foell et al., 1992).

In 2015 the DISCOL site was revisited and sampled twice (RV Sonne cruises SO242-1 and SO242-2). The initial cruise was conducted in the summer and primarily conducted detailed acoustic and image-based mapping of the plough tracks using autonomous underwater vehicles (AUVs) and ship-based sensors. This initial cruise also towed an epibenthic sled (EBS) several times across the seafloor, removing the top $20 \mathrm{~cm}$ of seafloor in trenches of $\sim 2 \mathrm{~m} \times 500 \mathrm{~m}$. These sled deployments were conducted to more accurately simulate the upper sediment removal envisioned as a likely consequence of mining. The second of these cruises focused on the detailed photographic study of the historic and recent disturbances mapped during the first cruise.

For investigation of megafauna, including fishes, the Alfred Wegner Institute (AWI) OFOS LAUNCHER towed camera system was used to conduct photographic transects of the seafloor. The OFOS LAUNCHER is identical to the OFOBS system described in Purser et al. (2018a), with the exceptions that the OFOS was not equipped with INS, side scan or forward-facing sonar systems. OFOS was flown at a height of $\sim 1.7 \mathrm{~m}$ above the seafloor and used a 23 megapixel downward-looking still camera (iSiTEC, CANON EOS 5D Mark III) to take images every $15 \mathrm{~s}$, each of which also captured the laser points projected by a tri-laser $(50 \mathrm{~cm}$ spacing) sizing device (iSiTEC, custom built). Ship speed was maintained at $0.2-0.4 \mathrm{kn}$.

Given the high heterogeneity of the seafloor area studied, each image was manually assessed to represent one of a range of disturbance categories. These were (1) "Reference" areas, not directly within the target circle of seafloor 


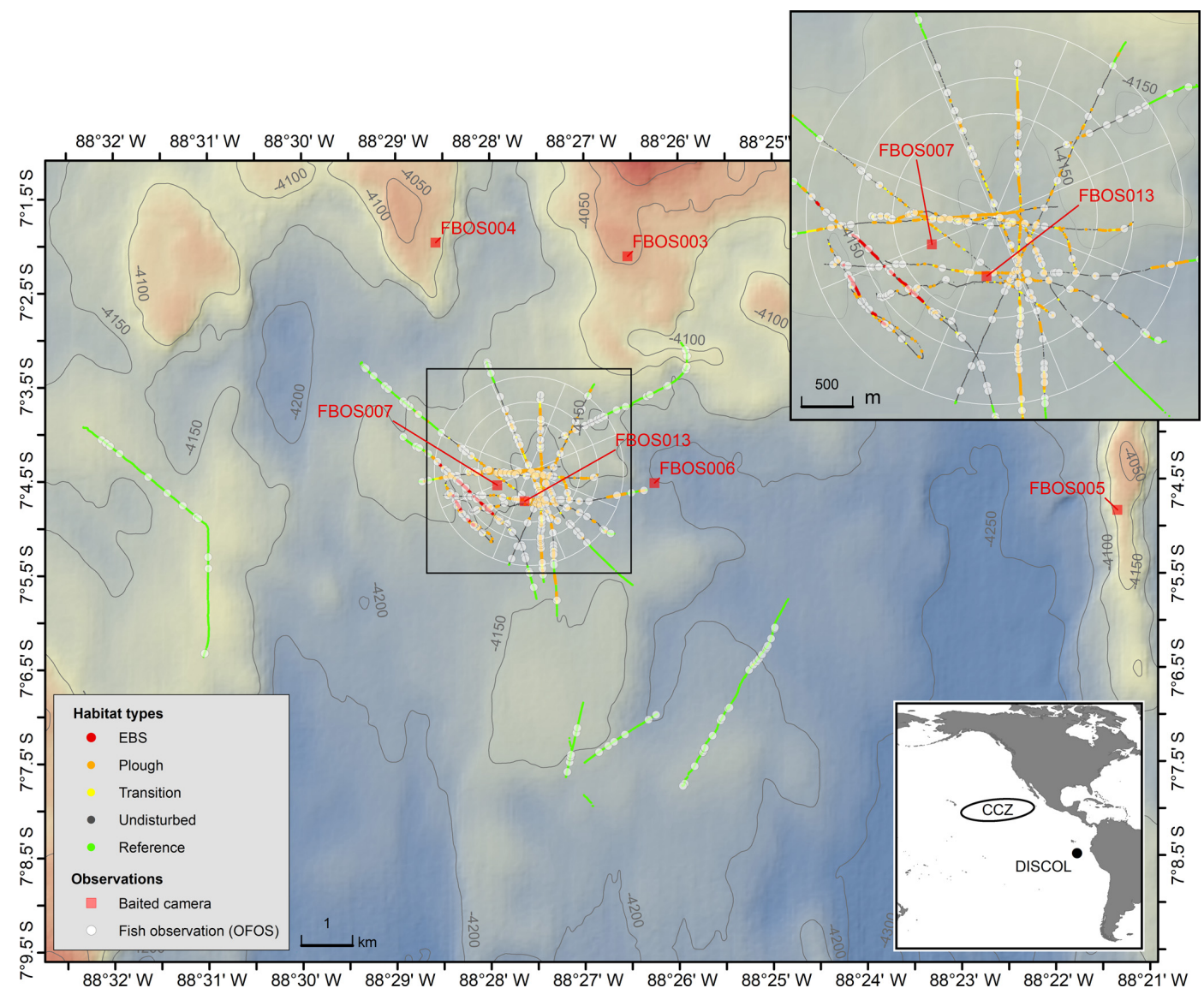

Figure 1. Map of the DISCOL study site showing the distribution of OFOS camera transects (colors indicate the five habitat types), the OFOS-based fish observations (white circles) and the location of the baited camera deployments (red squares). The white circular pattern and spokes show the location and extent of the DEA.

ploughed in 1989 (DEA), (2) "Undisturbed" areas within the central DEA circle, but not actually impacted by the plough harrow directly, (3) "Transition" images, within which both the edge of a plough track was visible as well as surrounding seafloor, (4) "Ploughed" images within which only ploughed seafloor was visible, and (5) "EBS" areas, disturbed a month prior to SO242-2 by the towed epibenthic sled deployed by SO242-1. These five disturbance categories represent increasing levels of physical disturbance.

The image area captured within each image was determined by measuring the spacing of the laser points in a subset of 3663 images using the PAPARA(ZZ)I software application (Marcon and Purser, 2017). The image area of all remaining images was calculated from the camera altitude (distance to seafloor) using a second-order polynomial regression of the laser-based measurements. The average seafloor image area was $5.71 \pm 3.44 \mathrm{~m}^{2}$ (interquartile range $4.45-6.25 \mathrm{~m}^{2}$ ). In some instances, the camera was manually triggered to capture images of fishes that would have been missed in between timed images or to capture a fish at a more suitable angle for identification. Images were manually anno- tated for fishes using a variety of published keys. For data on octopi, see Purser et al. (2017). Fish density was estimated by dividing the number of fish viewed in regular timed images by the area photographed. Manually triggered images were not included in density estimates, as these would present a positive bias towards images with fish in them. Diversity was evaluated using rarefaction curves (on all images, timed and manually triggered, because this approach only requires positive occurrences) to enable comparisons between habitat types that were not sampled at the same intensity.

OFOS transects often crossed several habitat types, so for fish density estimates, the images from each transect were divided into habitat type transects. For some habitat transects, there were very few images collected. We eliminated those habitat transects which were so small that they were unlikely to contain at least one fish. We based this assessment on the mean density of all habitat transects (both large and small) of 30.6 fish ha ${ }^{-1}$, translating to a threshold sample area of $330 \mathrm{~m}^{2}$. If used in the analysis, these small habitat transects would bias the results either towards zero estimates if no fish were present in the small image set or towards incorrectly 
high estimates if a few fish happened to be present. Fish density was compared between habitat types using a permutational ANOVA on a Euclidean distance matrix to account for uneven sample sizes and non-normal data distribution.

Baited cameras are now a widely used tool to make a census for marine fishes (Bailey et al., 2007) because they can attract often sparsely distributed animals to within the census view, including some that might avoid active camera survey tools. Thus, for fully describing diversity and species abundances within a regional fish assemblage, they are indispensable. However, in contrast to transect methods, they are more difficult to use for estimations of accurate animal densities (Priede and Merrett, 1998; Yeh and Drazen, 2011).

During the first post-disturbance cruise in 1989 and 3 years later in 1992 (Sonne cruises 61 and 77), free-fall baited cameras (free-fall baited observing systems - FBOSs) were deployed (Brandt et al., 2004). These utilized a Benthos $35 \mathrm{~mm}$ survey camera and strobe. Bait (a single 500-1000 g carangid or lutjanid) was attached to a rod or placed in a small clear plastic tube $\sim 1 \mathrm{~m}$ from the camera, resting on the seafloor. Oblique images of $\sim 1.7 \mathrm{~m}^{2}$ of the seafloor were taken every 2 to $5.5 \mathrm{~min}$ for $\sim 24$ to $55 \mathrm{~h}$, averaging $725 \pm 43$ images per deployment. Animals were counted in each image. Metrics extracted from the imagery include the maximum number of each taxon visible in any one image over the camera deployment $(\mathrm{MaxN})$, the time of first arrival for each taxon $\left(T_{\text {arr }}\right)$ and the proportion of images in which a taxon was present for a camera deployment (Yeh and Drazen, 2011; Linley et al., 2017; Leitner et al., 2017). Only species that were clearly attracted to the bait were enumerated. This eliminated species that were photographed as they were simply drifting or crawling through the field of view, such as medusa and holothurians. Further, many small amphipods were often present at the bait but could not be reliably counted and so are not included. Deployments in 1989 were made within both the reference and disturbance areas, and a PERMANOVA test was used to compare community compositions on a Bray-Curtis similarity matrix based on squareroot-transformed MaxN data.

\section{Results}

\subsection{Photographic transects}

Twenty OFOS transects were performed, resulting in 46 habitat transects (Fig. 1). From these a total of 16733 images were examined, with 306 fishes observed in 300 images (Table 1). Fishes were represented by 14 taxa (not including the category "Unidentified fish"; Fig. 2). Several groups were distinct but could not be identified to species, whereas others were only identifiable to a genus or family. The most common species observed was the benthic Ipnops cf. meadi, representing $61 \%$ of the fish observations. The ophidiids were the most speciose family, observed with six operational tax-

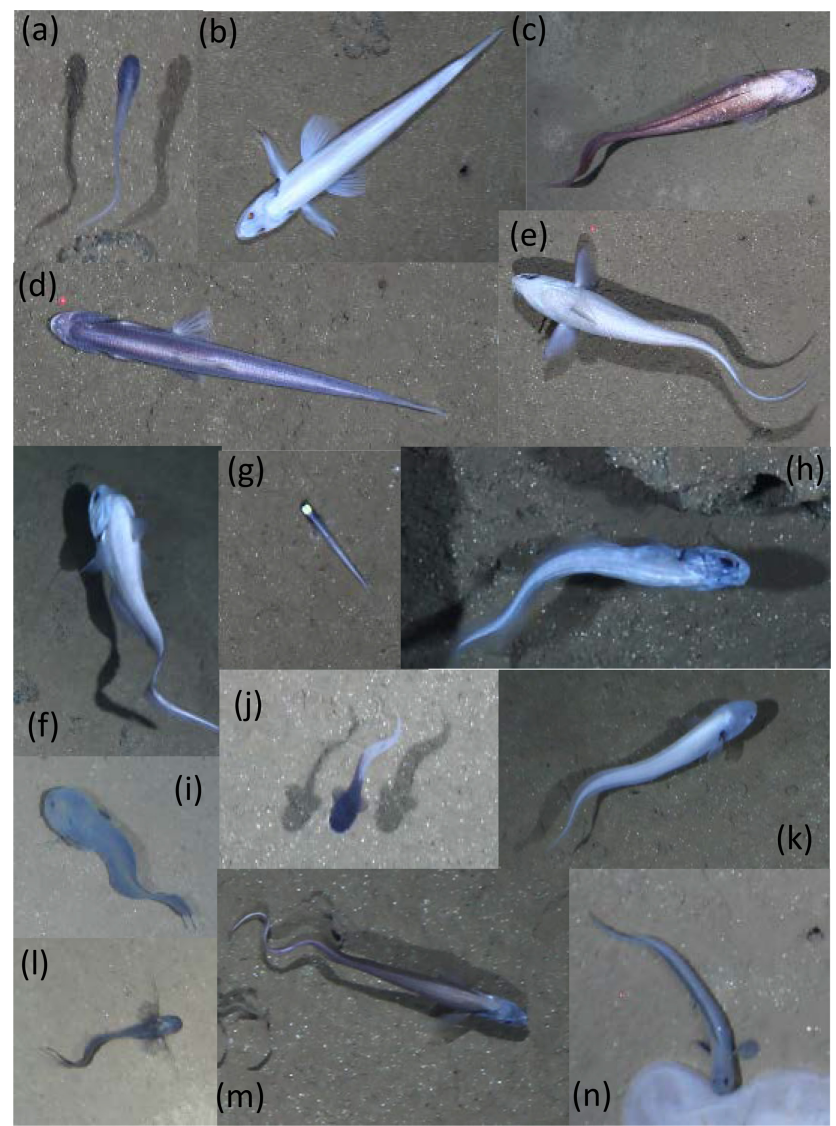

Figure 2. Representative images of OTUs identified in the DISCOL region during the 2015 survey. (a) Bassozetus cf. nasus. (b) Bathysaurus mollis. (c) Bathyonus cf. caudalis. (d) Bathytyphlops cf. sewelli. (e) Coryphaenoides armatus/yaquinae. (f) Coryphaenoides leptolepis. (g) Ipnops cf. meadi. (h) Leucicorus sp. (i) Liparidae gray morphotype. (j) Liparidae bicolor morphotype. (k) Bassozetus sp. B. (l) Ophidiidae sp. 3. (m) Porogadus sp. (n) Pachycara cf. nazca.

onomic units (OTUs), some of which were distinct but could not be identified conclusively.

Across the five different habitat types, sampling effort was very uneven. Within the full dataset, images taken of reference area habitat and in unploughed habitat within the experimental area were most abundant (Table 1). Seafloor images showing the disturbed habitat types (transient, ploughed and EBS tracks) were less numerous. For all the data combined, as well as for the unploughed habitat type alone, rarefaction curves suggested adequate sampling as an asymptote was beginning to be reached in both cases (Fig. 3). However, within the other habitat types, rarefaction curves suggested that more sampling was required to fully capture the fish diversity. Thus, the use of estimated species richness was needed for diversity comparisons. Interestingly, the disturbed habitat types had higher rarified diversity (ES 26) than the reference area or neighboring unploughed habitat (Fig. 3). 
Table 1. Numbers of photo transect (OFOS system) observations (all images/timed images only) for fishes in the DISCOL area by habitat type 26 years after initial experiment. The percentages of images with fishes are calculated from the timed images only.

\begin{tabular}{|c|c|c|c|c|c|c|c|}
\hline \multirow[t]{2}{*}{ OTU } & \multirow[t]{2}{*}{ Family } & \multicolumn{6}{|c|}{ Habitat type } \\
\hline & & Total & Reference & Undisturbed & Transition & Ploughed & EBS \\
\hline Bathysaurus mollis & Bathysauridae & $13 / 11$ & $2 / 1$ & $5 / 4$ & 2 & 2 & 2 \\
\hline Bathytyphlops cf. sewelli & Ipnopidae & 5 & 0 & $3 / 3$ & 0 & 2 & 0 \\
\hline Ipnops cf. meadi & Ipnopidae & $188 / 178$ & $68 / 64$ & 97/91 & 11 & 11 & 1 \\
\hline Liparidae & Liparidae & $4 / 3$ & 1 & $3 / 2$ & 0 & 0 & 0 \\
\hline Coryphaenoides armatus/yaquinae & Macrouridae & $6 / 5$ & 0 & $3 / 3$ & $3 / 2$ & 0 & 0 \\
\hline Coryphaenoides leptolepis? & Macrouridae & $1 / 0$ & 0 & $1 / 0$ & 0 & 0 & 0 \\
\hline Bassozetus cf. nasus & Ophidiidae & 6 & 2 & 1 & 2 & 1 & \\
\hline Bassozetus sp. B & Ophidiidae & 2 & 0 & 1 & 1 & 0 & 0 \\
\hline Bathyonus caudalis & Ophidiidae & $30 / 26$ & 8 & $15 / 12$ & 2 & $3 / 2$ & 2 \\
\hline Leucicorus sp. & Ophidiidae & $3 / 2$ & $3 / 2$ & 0 & 0 & 0 & 0 \\
\hline Ophidiidae sp. 3 & Ophidiidae & 6 & 1 & 2 & 1 & 2 & 0 \\
\hline Ophidiidae unided & Ophidiidae & $16 / 14$ & 2 & $8 / 6$ & 1 & 5 & 0 \\
\hline Porogadus sp. & Ophidiidae & 11 & 4 & 3 & 3 & 1 & 0 \\
\hline Pachycara spp. & Zoarcidae & $4 / 2$ & $2 / 1$ & $2 / 1$ & 0 & 0 & 0 \\
\hline Unidentified fish & & $11 / 10$ & $4 / 3$ & 4 & 0 & 2 & 1 \\
\hline No. fish & & $306 / 281$ & $97 / 89$ & $148 / 133$ & $26 / 25$ & $29 / 28$ & 6 \\
\hline No. OTUs & & 14 & 10 & $13 / 12$ & 9 & 8 & 3 \\
\hline No. images & & 16733 & 5964 & 7155 & 1209 & 2055 & 350 \\
\hline No. images with fish & & $300 / 275$ & $97 / 89$ & $145 / 130$ & $23 / 22$ & $29 / 28$ & 6 \\
\hline Images with fish (\%) & & $1.6 \%$ & $1.5 \%$ & $1.8 \%$ & $1.8 \%$ & $1.4 \%$ & $1.7 \%$ \\
\hline
\end{tabular}

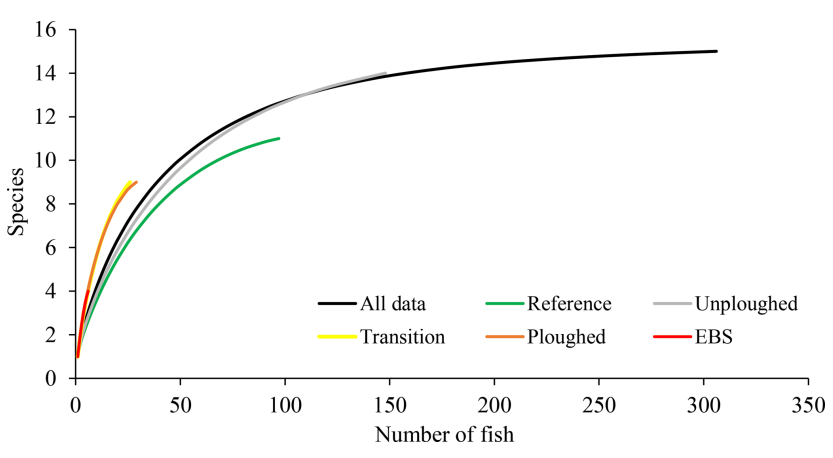

Figure 3. Rarefaction curves, estimated species richness as a function of the number of fish observations, for OFOS transects across habitat types.

Fish densities were highly variable. Across all habitat transects, seafloor areas imaged ranged from 355 to $7798 \mathrm{~m}^{2}$, and fish density ranged from 0 to $71.4 \mathrm{fish} \mathrm{ha}^{-1}$. Average fish density was $30.2 \pm 18.2$ fish ha $^{-1}$ (Fig. 4). Across the habitat types, density did not vary significantly (PERMANOVA; $p>0.05)$. The density of the most common fish, I. meadi, could also be estimated and ranged from 0 to 68 fish ha $^{-1}$, averaging 18.4 $\pm 17.5 \mathrm{fish} \mathrm{ha}^{-1}$ across all habitat types (Fig. 4). Its density was significantly lower in the ploughed habitat type compared to undisturbed and reference habitats. Only a single I. meadi was found in the EBS habitat type (Table 1), but this individual did not occur in a habitat transect of suf- ficient length for density estimation. Ipnops meadi density in the two habitat transects available for analysis was zero.

Since the time of initial disturbance fish density in the DEA varied. No fish were observed 6 months after disturbance, then fish density increased at year 3 and returned to pre-disturbance density levels after 7 years (Fig. 5; Bluhm, 2001). At this time, ophiuroids, holothurians, fish and hermit crabs were observed in the plough tracks. We examined this data (1989-1996) and the 2015 data for the reference, ploughed and unploughed habitat types using a twofactor PERMANOVA. Habitat type and time were significant predictors of fish density, with lower fish densities in the ploughed habitat $(p<0.01$; Table $\mathrm{S} 1$ in the Supplement). Also, the differences in the densities of fish across the three habitat types changed significantly with time since the disturbance (habitat $x$ time, $p<0.05$ ). Fish density in the ploughed habitat was significantly $(p<0.05)$ lower than the other habitat types right after the disturbance, marginally lower at 6 months after disturbance $(p=0.057)$, and significantly lower at 3 years after disturbance. At 7 years the undisturbed habitat type in the DEA had higher fish density than the reference area. At 26 years, as already mentioned, there was no difference between habitats. Fish densities were similar to levels found in the undisturbed habitats and the reference area at 3 years after disturbance but higher than other times (Fig. 5). It was not possible to evaluate the time series data for I. meadi, as Bluhm (2001) did not publish species specific results. 


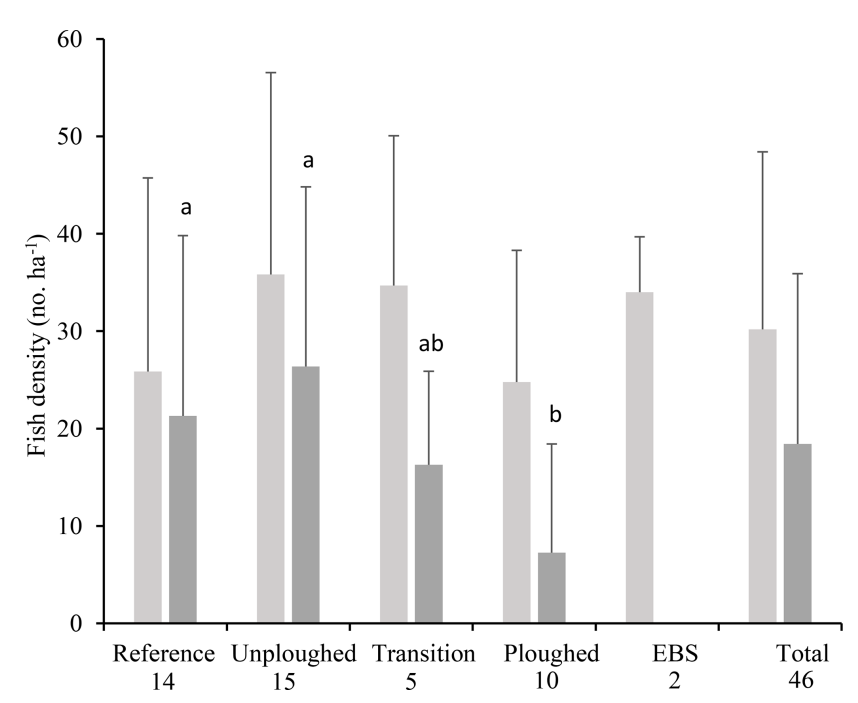

Figure 4. Total fish (light gray) and I. meadi (dark gray) density (mean and standard deviation) from the 2015 OFOS transects by habitat type (timed images only) and for the entire dataset. The number of separate transects for each habitat type is given under its name. Letter symbols for each habitat indicate significant differences in I. meadi density $(p<0.05)$.

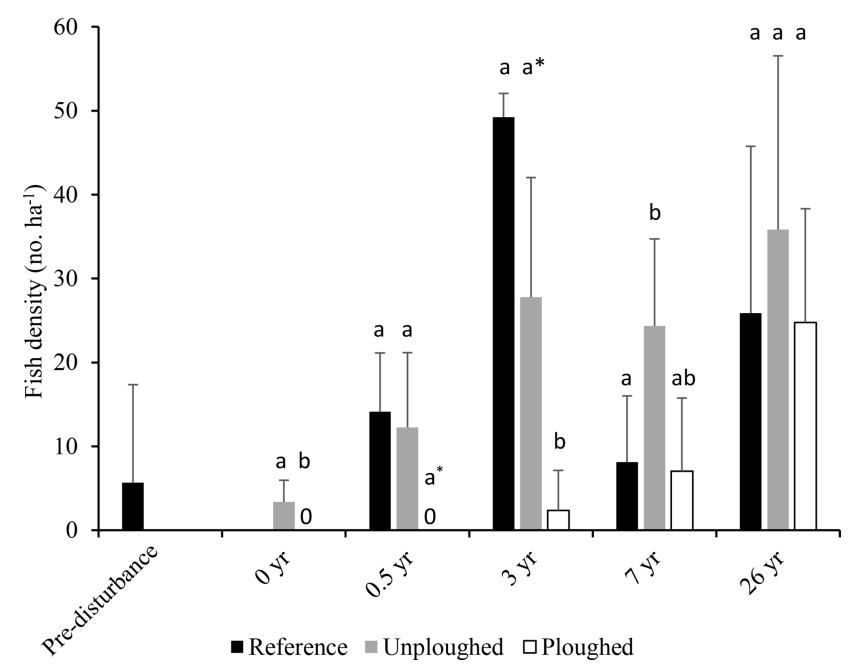

Figure 5. Fish density (in number per hectare; mean and standard deviation) from pre-disturbance (1989) to 26 years after disturbance (2015) in the reference area and in the ploughed and unploughed habitats of the DEA. Data from pre-disturbance to 7 years after disturbance are from Bluhm (2001). Letter symbols for each time indicate significant differences between habitat types $(p<0.05)$. At 0.5 years the asterisk indicates a marginal significant difference $(p=0.057)$.

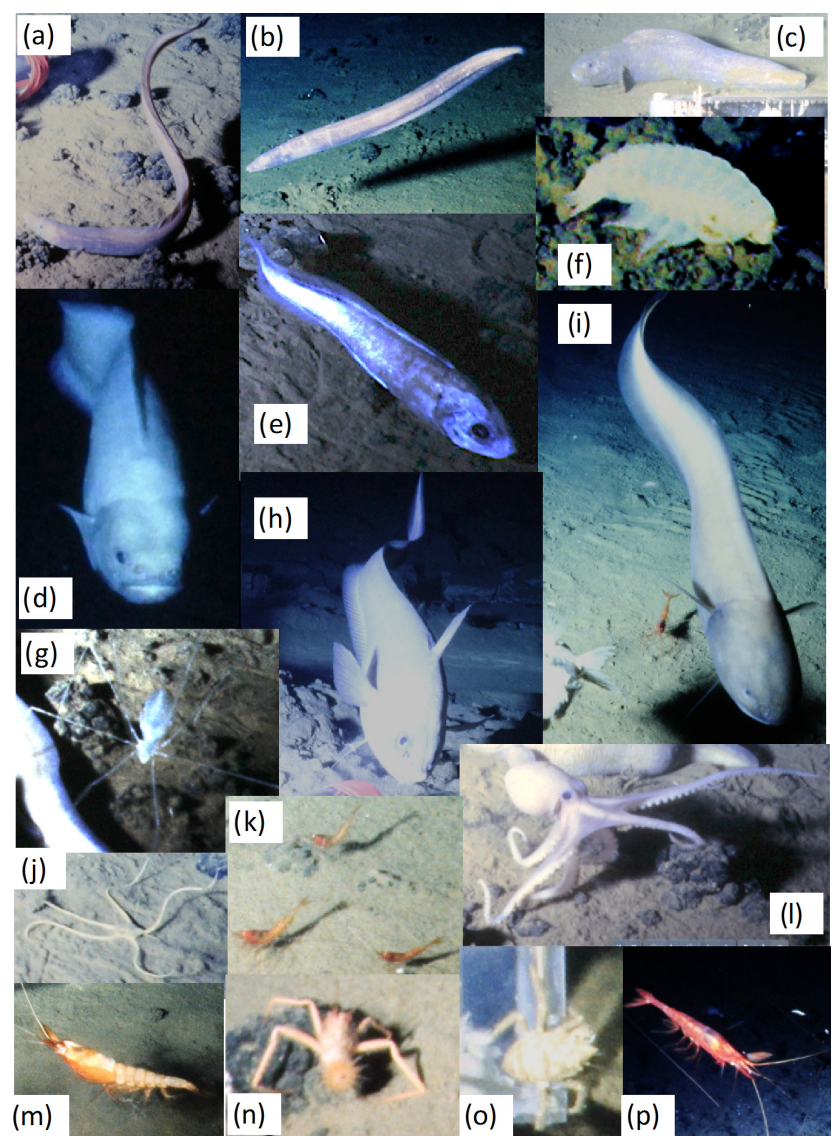

Figure 6. Representative images of OTUs identified using baited cameras in the DISCOL region. Photos taken in 1989 and 1992. (a) Illypohis sp. (b) Synaphobranchidae. (c) Pachycara nazca. (d) Barathrites iris. (e) Leucicorus sp. (f) Large amphipod, likely Eurythenes sp. (g) Munnopsidae. (h) Coryphaenoides sp. (i) Bassozetus cf. nasus. (j) Ophiuroidea. (k) Hymenopeneus nereus. (l) Octopoda (Vulcanoctopus sp.). (m) Benthiscymus sp. (n) Probeebei mirabilis. (o) Munnidopsis sp. (p) Cerataspis monstrosus.

\subsection{Baited camera observations}

Six baited camera deployments were conducted: five in 1989 and one in 1992 (Table 2). Six taxa of fishes were identified (Fig. 6). The most abundant (MaxN) taxon in the deployments was the eelpout Pachycara nazca. This species occurred in all six deployments, reached a MaxN of nine in two of the deployments and on average was present in $55 \%$ of the images. Individuals of the rattail Coryphaenoides sp. were either $C$. armatus or $C$. yaquinae, or both were present, but we could not differentiate them in the photographs. This taxon was present in all of the deployments but was observed on average in only $2.1 \%$ of images, and MaxN was never more than 2. Several ophidiids and a synaphobranchid eel were also observed. Ophidiids were generally rare and seen infrequently, though Bassozetus nasus did generally persist at the bait when observed. 
Table 2. Deployment MaxN for each bait-attending species by camera deployment (FBOS system). DEA - DISCOL experimental area.

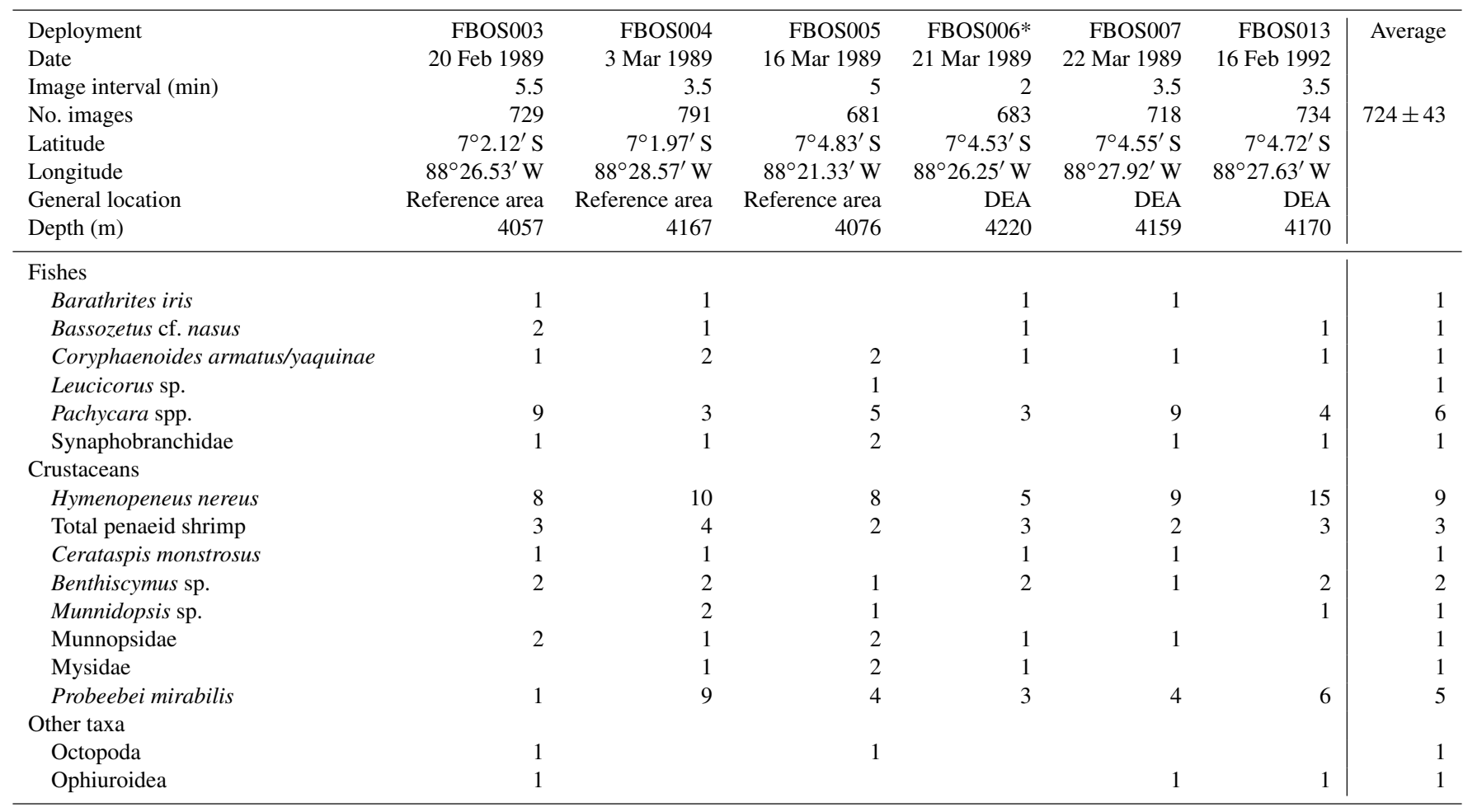

* Deployment filmed a plough-harrow track.

The baited camera also attracted nine taxa of invertebrates (Table 2). The small shrimp Hymenopeneus nereus was present in all of the deployments in relatively large numbers (average $\mathrm{MaxN}=9$ ), with up to 15 visible at one time, and was present on average in $63 \%$ of the images. The hermit crab Probeebei mirabilis was also observed in every deployment but in varying numbers (from one to nine) and in $29 \%$ of the images. Penaeid shrimp were also observed in every deployment and were the third most abundant and common scavenging species. Two species were identified, Cerataspis monstrosus (identified as Plesiopenaeus armatus in earlier papers; Leitner et al., 2017) and Benthiscymus sp. Frequently, these could not be distinguished, as they differ in the shape of the antennal scale and rostrum, which were not always clearly visible. Large munnopsid isopods were seen in all but one deployment but did not remain in the field of view for long. Ophiuroids were not abundant or common, being observed in three deployments as single individuals, but they stayed in the field of view for a long time (high persistence values).

Two of the camera deployments in 1989 were made in the disturbance area 6 months after the event. In one of these deployments there was no obvious sign of disturbance in the limited field of view. In the other, a plough-harrow track was clearly visible (FBOS006; Table 2). Low numbers of the benthic eelpout, P. nazca, were observed during this deployment.
This deployment also had the lowest numbers of the benthic shrimp, H. nereus. However, the community composition did not vary significantly between the 1989 deployments inside the disturbance experiment area and reference areas (PERMANOVA; $p>0.05$ ). Further, the times of first arrival of the scavengers were variable between deployments and not consistently longer at the disturbance area, except for B. iris (Table S2).

Overall, the diversity observed with the small number of camera deployments was fairly uniform, as evident from the plateau reached in both rarefaction and species accumulation curves (Fig. 7). This was the case for all scavengers and for the fishes alone. The baited cameras observed fewer taxa of fishes compared to the photo transects (Tables 1 and 2). Many of the fishes observed in the photo transects included less mobile benthic species such as members of the Ipnopidae, Bathysauridae and numerous unidentified ophidiids. However, the baited camera deployments identified two fish species that were not observed in the photo transects, Barathrites iris and a Synaphobranchid eel, both mobile scavengers. 

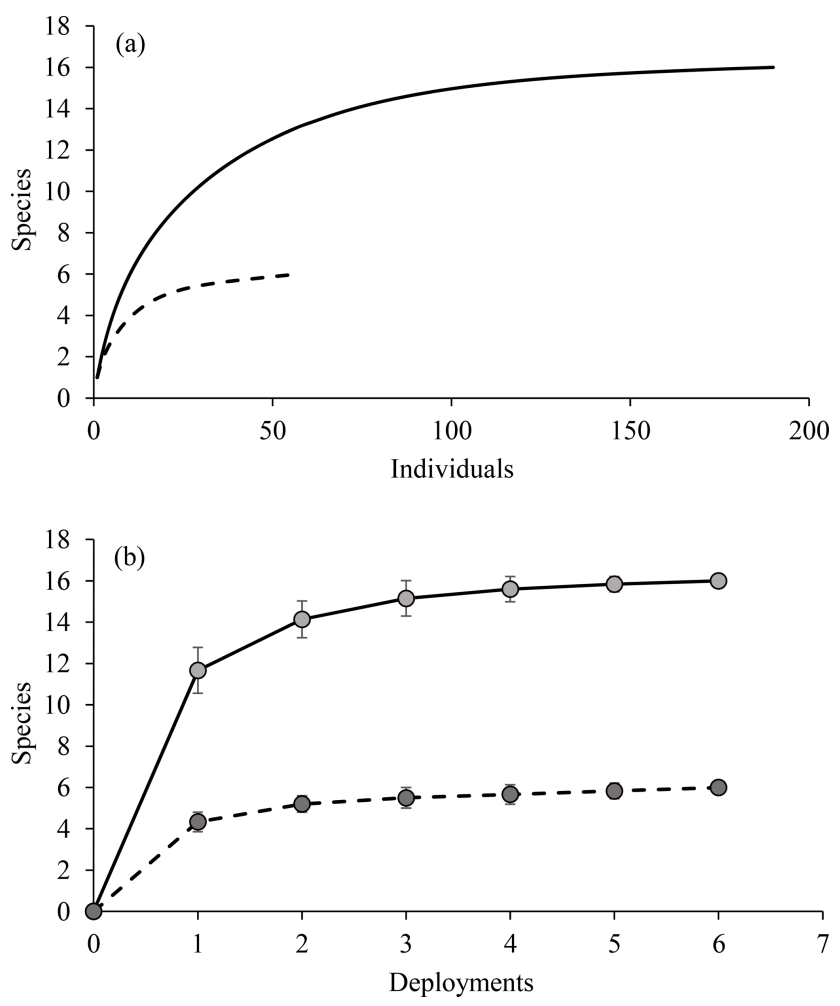

Figure 7. (a) Rarefaction and (b) species accumulation curves for baited camera observations. Solid lines represent all data, and dashed lines are fishes only (both based on MaxN data).

\section{Discussion}

\subsection{A description of the fish and scavenging community and relationship to past DISCOL studies}

We present some of the first detailed fish assemblage information for the abyssal eastern Pacific. Earlier studies at the DISCOL site presented limited fish assemblage results from the first few years of the experiment and report finding eight fish taxa, with Ipnops sp. being the most abundant (Bluhm, 1994). All of the taxa that were observed in these initial investigations were also present in our 2015 survey results, with the exception of Halosaurus sp. Moreover, we observed six additional taxa in 2015, and together with analysis of the 1989-1992 baited camera deployments, we have observed a total of 16 taxa. Interestingly, the earlier camera transect surveys flew the camera system higher off the bottom (3-3.5 m vs. $1.7 \mathrm{~m}$ ), which is perhaps more appropriate for the survey of larger, mobile fishes. Advances in photographic identification of abyssal fishes across the Pacific and improvements in photographic quality have resulted in the greater detail in the present analysis.

The baited camera deployments provided additional information on the DISCOL fish community and also provided data on scavenging invertebrate fauna. Past taxonomic works have used trapped specimens to document the pres- ence of the eelpouts $P$. nasca and $P$. bulbiceps (Anderson and Bluhm, 1997) and the ophidiid B. iris (specimen deposited at the Senckenberg Museum). The physical specimens provide some vouchers for taxa that were identified from photographs. Two taxonomic studies used the baited camera imagery to tentatively identify the ophidiid Bassozetus nasus (Nielsen and Merrett, 2000) and large munnopsid isopods which were thought to belong to the genus Paropsurus (Brandt et al., 2004). Bluhm et al. (1995) briefly states that $P$. mirabilis and ophiuroids were commonly seen in the baited camera photos, but these results were not given in any detail. We show that the eelpouts, the shrimp $H$. nereus and hermit crabs are indeed common and regular bait-attending fauna at this site (see below for comparisons to other abyssal regions).

\subsection{Evaluation of the fish community response to disturbance and potential recovery}

Our results, 26 years after disturbance, when compared to earlier sampling, provide some insight into the recovery potential of the fish fauna. The striking result found by Bluhm (2001) was that no fishes were observed in the disturbance area within 6 months of the disturbance; however, we show the presence of fish and scavenging invertebrates at this time from baited camera deployments. Samples sizes were low, but the community seems comparable to that in the reference areas at the same time. It seems likely that the scavengers were attracted from a larger area that could have included the proximate reference or undisturbed areas, as suggested by the similar arrival times of the scavengers in reference and disturbance deployments. This could occur even if these animals were not commonly residing in the disturbance area due to habitat or prey community alteration because the DISCOL experiment created a patchwork of habitats over a scale as small as tens of meters (Fig. 1).

The fish community remains affected by the DISCOL experiment even after 26 years. Total fish density in the ploughed habitat of the DEA increased over time and in relation to the reference and undisturbed habitat, suggesting recovery. It should be noted that large interannual changes were evident at the reference site, with fish densities peaking 3 years after disturbance and at high levels again at 26 years (Fig. 5). An increase in megafaunal density over the first 7 years of the experiment was already documented and hypothesized to be the result of increased phytodetrital food flux and growing populations regionally (Bluhm, 2001). Such variation in megafaunal abundance is a regular feature of abyssal communities (Kuhnz et al., 2014; Ruhl and Smith, 2004). Comparisons between habitats at a point in time can provide a more robust means to assess recovery after plough disturbance (Miljutin et al., 2011). We found no differences in total fish density between the disturbed and undisturbed habitats at 26 years. Further, diversity (ES 26) was slightly higher in the disturbed habitat areas, although 
with relatively small sample sizes. However, the most common fish, I. meadi, which makes up more than half of all the fish observations, had only a third of the density in 26-yearold plough tracks compared to undisturbed and reference areas, and only one individual was seen in the fresh EBS tracks (Fig. 4). This fish is found in the undisturbed habitat which occurs in a patchwork with the disturbance tracks; hence regional reductions in population density are unlikely. Rather it seems that $I$. meadi actively avoids the plough tracks, showing that even the mobile fish community remains affected by the disturbance after more than 2 decades. This species' response likely relates to its biology as a rather sedentary, small benthic fish that, based on limited data, feeds on polychaetes, small bivalves and crustaceans (Nielsen, 1966; Crabtree et al., 1991). Its prey may not have recovered in the tracks (Jones et al., 2017; Borowski, 2001). Most of the other fishes observed are benthopelagic and when swimming across a habitat mosaic might as easily be seen over an old plough track as over other habitats. Even if benthopelagic species tend to favor undisturbed habitat, this would be difficult to see in data at such a small scale. Our other benthic species include the lizardfish $B$. mollis, which preys on mobile fishes and shrimps, and $B$. sewelli, which is a larger member of the Ipnopidae but was observed too infrequently to assess habitat preferences (Table 1).

Conclusions about fish community recovery over time must be taken with caution. With a sparsely distributed fauna and the high variability in density, there are limits on statistical power and thus our confidence. The earlier DISCOL surveys differed in methodology to the current surveys, including average altitude of the camera above the bottom, image quality and attention to the fishes. Our diversity estimates may well be higher as a result. Density estimates could also be affected by these same factors. The most common fish in the surveys, I. meadi, is relatively small and despite reflective eyes (Fig. 2) may have been more visible in our 2015 surveys in closer proximity to the seafloor. The influence many of these parameters have had on abundance estimations of fauna in the DISCOL region has been investigated in detail for a region of the DEA which was surveyed several times during the initial 7-year period and again in 2015. In 2015, the OFOS was deployed at 1.7 and $4 \mathrm{~m}$ in this region, and additionally an AUV was flown at $5 \mathrm{~m}$ to image the same region of seafloor. The results from these comparative studies (Purser et al., 2019) show the sensitivity of density and diversity indices in the DISCOL area to changes in flight height, illumination and camera type. Larger megafauna, such as fish, were clearly visible in images collected from higher altitudes, therefore resulting in both higher diversity and abundance estimates for a given transect length than achieved with lower-flying camera systems. Certainly, methodology plays a very important role in determining the accuracy of sampling strategies in this ecosystem for determination of these parameters.
Our results add to a growing body of literature that generally finds little or partial recovery of faunal communities, even decades after simulated mining disturbances. Epifaunal megafauna density was considerably lower in disturbance tracks made 20 and 37 years prior to resurvey during the OMCO experiment in the CCZ (Vanreusel et al., 2016). Meta-analyses of abyssal disturbance experiments in the CCZ suggest that recovery of density and diversity is faster in mobile than sedentary fauna (Gollner et al., 2017; Jones et al., 2017). For instance, the mobile holothurian community appears to have recovered from disturbance in terms of density and community composition at the DISCOL site after 26 years (Stratmann et al., 2018). Most holothurians are detrital deposit feeders, and their food source settling from above may not be greatly affected by the plough disturbance, whereas some fishes, such as I. meadi, likely rely upon epifaunal and infaunal macrofauna for food. The meiofauna and macrofauna have not recovered completely after 26 years in the CCZ (Miljutin et al., 2011) or after 7 years at the DISCOL site (Borowski, 2001). Some of the variation in the recovery potential observed between studies is undoubtedly derived from the variation in disturbance type and intensity. The direct benthic scale of actual nodule-mining activities is suggested to be from 300 to $600 \mathrm{~km}^{2} \mathrm{yr}^{-1}$ for a single mining license (Oebius et al., 2001; Levin et al., 2016). While it may seem that a local disruption in I. meadi's distribution is a mild fish community effect 26 years after disturbance, it must be kept in mind that the DISCOL experiment did not completely disturb the DEA and that the scale of this experiment is very small in relation to industrial scale deep-sea mining. We argue that at industrial scales of seafloor disturbance, I. meadi could exhibit major regional reductions in population density that would last for decades, and such effects could extend to other species as well. Fishes may avoid direct mining activities but experience long-term habitat losses at spatial scales that seem very likely to result in regional population consequences. Plumes of sediment from collectors or from discharge of the ore dewatering plume (Rolinski et al., 2001) will greatly expand this area and magnitude of effect. Therefore, it seems unlikely that the small-scale disturbance experiments, such as DISCOL $\left(\sim 10.8 \mathrm{~km}^{2}\right)$, will be adequate for evaluating the potential effects of full scale nodule mining. Further, the physical disturbances made in all experimental studies to date have not been directly reminiscent of the impacts actual mining will make in terms of volumes of surface sediment removed or displaced, subsequent sediment compaction, or generation of the high-resolution topographical changes associated with the ridges and troughs likely to result from tracked mining vehicle movement (Jones et al., 2017, 2018; Doya et al., 2017). 


\subsection{Comparison of the DISCOL fish and scavenger communities to those within the $\mathrm{CCZ}$}

Nodule mining is likely to affect very large areas of the seafloor over decades (Wedding et al., 2015). Mobile fishes and other scavengers likely have the greatest ability to migrate away from mining disturbances, but they may be affected regionally through the redistribution of prey resources and sublethal effects from toxic metals or sediment plumes. Consequently, the biogeographies of taxa, even mobile species, are an important input to spatial management approaches (Watling et al., 2013). The scale of species distributions will help determine where and how large reserve areas should be in order to protect species. Comparison of the present findings in the South Pacific to those in the CCZ polymetallic nodule province to the north, across the equatorial upwelling, provide some insight into the ranges of abyssal fishes and scavengers in this mining-relevant region. Past studies frequently combined fish and scavenger taxa into larger functional groups such as megafauna (Jones et al., 2017), but some studies have presented lists of species, which are the focus of the comparison here.

A number of the fish taxa observed with camera transects in the CCZ (Pawson and Foell, 1983; Radziejewska and Stoyanova, 2000; Tilot, 2006; Amon et al., 2017) have also been identified in the DISCOL area, suggesting large species distributions (Table 3); 10 of the 14 taxa in the DISCOL region are shared with the CCZ. Four taxa were identified from DISCOL that were not previously identified from the CCZ region, none of which were abundant. Four fishes were observed in the various CCZ studies but not at the DISCOL site. A number of abyssal species have pan-Pacific and even global distributions (Priede, 2017). However, we are not suggesting that there is only a single community of fishes and scavengers integrated over thousands of kilometers. Rather it is likely that there are some species from this community, such as those that occur in both the DISCOL and CCZ regions, with broad distributions that could recolonize a mining license area if extirpated by mining. The extent of such conclusions must be made with caution because the overlap between the two areas may be artificially high. Unrealistic overlap could arise due to the difficulty in identifying species from photographs, particularly those taken from high altitudes, and hence the use of genera and higher taxonomic categories. Further there are some taxa which can easily be confused depending upon image quality. For instance in the DISCOL site we identified the ophidiid, Porogadus sp., which has a long whip-like tail and narrow body similar to halosaurs which have been observed in the CCZ (Amon et al., 2017) and in an earlier study at the DISCOL site (Bluhm, 1994). We suspect that with increasing camera resolution and better taxonomic experience, photographic data and their analysis will improve greatly. Also, taxa are much more easily identified in oblique imagery. For instance, halosaurs have prominent high pectoral fins and a single short dorsal, whereas Poro- gadus has a long, low dorsal fin, all of which are seen in oblique imagery. We suggest the use of both oblique and vertical cameras on the same platforms in future studies. There has been some suggestion that oblique imagery would also alleviate avoidance issues with mobile taxa, but in the one abyssal study that used both oblique and vertical cameras, greater fish density was found in the vertical imagery (Milligan et al., 2016). Finally, collecting physical specimens and genetic data would be a great complement to the camerabased approach. Trawling for fish samples in mining claim areas will be challenging due to the great depth and the abundance of nodules, which can break nets and greatly damage specimens. Baited traps are effective for some of the fauna (Leitner et al., 2017; Linley et al., 2016).

The scavenging communities exhibit some interesting differences to those described from the eastern $\mathrm{CCZ}$ region and other abyssal Pacific locations. The dominant DISCOL scavengers were the shrimp $H$. nereus, eelpouts Pachycara spp. and the hermit crab P. mirabilis. The presence of large numbers of hermit crabs at the DISCOL site has been noted in earlier transect studies (Bluhm, 2001), and their large contribution to the scavenging community seems unique amongst abyssal scavenger studies. The most similar finding was a few hermit crabs (Sympagurus birkenroadi; $\mathrm{MaxN}=2$ ) attending bait from 2000 to $3000 \mathrm{~m}$ depths off Hawaii (Yeh and Drazen, 2009). The large numbers of $H$. nereus are similar to the community in the eastern CCZ (Leitner et al., 2017). However, the eastern CCZ fishes were dominated by Coryphaenoides spp., which were not abundant at the DISCOL site. Overall the DISCOL scavenging community appears to be more similar to that observed in the western CCZ, which hosted lower numbers of Coryphaenoides spp. and greater numbers of ophidiids and shrimp (Leitner et al., 2017). The differences from east to west in the CCZ have been postulated to be related to the lower surface productivity in the west. Indeed, more oligotrophic regions have been shown to shift the dominance of the scavenging fishes from macrourids to ophidiids (Linley et al., 2017; Fleury and Drazen, 2013). However, the average long-term chlorophyll concentration at the DISCOL site estimated from the MODIS satellite $(30 \times 30 \mathrm{~km}$ box from 2006 to 2016) is about 1.5 times higher $\left(0.22 \mathrm{mg}\right.$ chl $\left.-a \mathrm{~m}^{-3}\right)$ than that reported by Leitner et al. (2017) in the eastern CCZ. Whether the community differences observed between the DISCOL and CCZ regions are the result of variations in overlying productivity, species distributions or other habitat factors cannot be discerned until a greater number of baited camera studies are conducted across the region.

In conclusion, the DISCOL site has a relatively diverse abyssal fish community dominated by Ipnops meadi. Fish density increased in the ploughed habitat type over time and became similar to undisturbed habitat types at 26 years after disturbance, but the density of I. meadi is still only a third of the undisturbed habitat types, indicating that the DISCOL experiment continues to affect the fish fauna through altered 
Table 3. Fish taxa occurrences from DISCOL and abyssal sites of the CCZ. bc - observed by baited camera only.

\begin{tabular}{|c|c|c|c|c|c|c|}
\hline Taxa & Family & $\begin{array}{l}\text { This } \\
\text { study }\end{array}$ & $\begin{array}{l}\text { Amon et al. } \\
(2016,2017)\end{array}$ & $\begin{array}{l}\text { Pawson and } \\
\text { Foell (1983) }\end{array}$ & $\begin{array}{l}\text { Radziejewska and } \\
\text { Stoyanova (2000) }\end{array}$ & $\begin{array}{l}\text { Tilot } \\
(2006)^{\mathrm{b}}\end{array}$ \\
\hline Bathysaurus mollis & Bathysauridae & $\times$ & $x$ & $x$ & & $x$ \\
\hline Halosauridae & Halosauridae & a & $\times$ & & & \\
\hline Bathytyphlops sewelli & Ipnopidae & $x$ & & & & \\
\hline Ipnops meadi & Ipnopidae & $x$ & $x$ & $x$ & $x$ & $x$ \\
\hline Liparidae & Liparidae & $x$ & & & & $x$ \\
\hline Coryphaenoides armatus/yaquinae & Macrouridae & $\times$ & $\times$ & $x$ & $\times$ & $x$ \\
\hline Coryphaenoides leptolepis? & Macrouridae & $\times$ & & & & \\
\hline Barathrites iris & Ophidiidae & $\mathrm{bc}$ & $\mathrm{bc}$ & & & $x$ \\
\hline Bassozetus sp. & Ophidiidae & $x$ & $x$ & $x$ & & \\
\hline Bassozetus sp. B (sp. 4 in Amon et al., 2017) & Ophidiidae & $x$ & $\times$ & & & \\
\hline Bathyonus caudalis (sp. 5 in Amon et al., 2017) & Ophidiidae & $x$ & $\times$ & & & \\
\hline Leucicorus sp. & Ophidiidae & $x$ & & & & \\
\hline Ophidiidae sp. 1 & Ophidiidae & & $x$ & & & \\
\hline Ophidiidae sp. 2 & Ophidiidae & & $\mathrm{bc}$ & & & \\
\hline Ophidiidae sp. 3 & Ophidiidae & $x$ & $\times$ & & & \\
\hline Ophidiidae & Ophidiidae & $x$ & & $x$ & & $x$ \\
\hline Porogadus sp. & Ophidiidae & $\times$ & & & & \\
\hline Typhlonus nasus & Ophidiidae & & & $x$ & & $x$ \\
\hline Histiobranchus bathybius & Synaphobranchidae & & $\times$ & & & \\
\hline Synaphobranchidae & Synaphobranchidae & $\mathrm{bc}$ & & & & $x$ \\
\hline Pachycara spp. & Zoarcidae & $\times$ & $x$ & & & \\
\hline Zoarcidae & Zoarcidae & & $\times$ & $x$ & & \\
\hline
\end{tabular}

a listed in Bluhm (1994). ${ }^{b}$ only these taxa out of 17 are given in the original reference.

distributions. At the temporal and spatial scales of industrial mining, changes in habitat availability could lead to population reductions even if fishes can avoid the direct activities of mining. The abyssal fish communities observed in the central eastern Pacific at DISCOL and the more northerly CCZ are similar with many shared taxa. However, further specieslevel identifications are required, which requires the collection of physical specimens through trawling or baited traps. The scavenging community in the DISCOL site is unique in the prevalence of the hermit crab, P. mirabilis, which does not appear in the CCZ in either camera transects or baited camera deployments. Not surprisingly, fishes and mobile scavengers appear generally to have large ranges but also large shifts in community composition across the CCZ (Leitner et al., 2017) and across the Equator. As commercial mining of polymetallic nodule provinces rapidly progresses, with commercial field trials commencing in the Belgian and German claim areas of the CCZ in the first months of 2019, gaining a better understanding of these remote ecosystems is of paramount importance. Until key fauna, such as the various benthic fish species utilizing these habitats, are better known, ensuring that appropriate management plans are developed to best minimize human impact during mining will be extremely challenging.

Data availability. All OFOS images and data collected during the RV Sonne SO242-2 cruise analyzed for this study are available with open access from the PANGAEA data repository:
https://doi.org/10.1594/PANGAEA.890634 (Purser et al., 2018b). Baited camera imagery is available through the BIIGLE data repository at https://annotate.geomar.de (last access: 18 July 2018).

Supplement. The supplement related to this article is available online at: https://doi.org/10.5194/bg-16-3133-2019-supplement.

Author contributions. JCD and ABL analyzed the data and wrote the paper. SM annotated the baited camera images and assembled the data. AP and YM designed and conducted the camera transect experiments, quantified image coverage, helped write the paper, and generated the map figure. JG digitized and archived the original baited camera images. All authors read and commented on the paper.

Competing interests. The authors declare that they have no conflict of interest.

Special issue statement. This article is part of the special issue "Assessing environmental impacts of deep-sea mining - revisiting decade-old benthic disturbances in Pacific nodule areas". It is not associated with a conference.

Acknowledgements. We thank the many DISCOL participants past and present who worked diligently to collect data over a 26-year 
study. We thank Kathy Dunlop and an anonymous reviewer for their careful comments on a draft of this paper. This is SOEST contribution no. 10754.

Financial support. The Gordon and Betty Moore Foundation provided funding for Jeffrey C. Drazen, Sage Morningstar and Astrid B. Leitner to participate in this study. The SO242 cruises and accompanying work was funded by the German Ministry of Education and Science (BMBF; grant number 03F0707AG) through the project Mining Impact of the Joint Programming Initiative Healthy and Productive Seas and Oceans (JPIO).

Review statement. This paper was edited by Tina Treude and reviewed by Kathy Dunlop and one anonymous referee.

\section{References}

Amon, D., Ziegler, A. F., Drazen, J. C., Grisschenko, A. V., Leitner, A. B., Lindsay, D. J., Wicksten, M. K., Voight, J. R., Young, C. M., and Smith, C. R.: Megafauna of the UKSRL exploration contract area and eastern Clarion-Clipperton Zone in the Pacific Ocean: Annelida, Arthropoda, Bryozoa, Chordata, Ctenophora, Mollusca, Biodiversity Data Journal, 5, e14598 https://doi.org/10.3897/BDJ.5.e14598, 2017.

Amon, D. J., Ziegler, A. F., Dahlgren, T. G., Glover, A. G., Goineau, A., Gooday, A. J., Wiklund, H., and Smith, C. R.: Insights into the abundance and diversity of abyssal megafauna in a polymetallic-nodule region in the eastern Clarion-Clipperton Zone, Sci. Rep.-UK, 6, 30492, https://doi.org/10.1038/srep30492, 2016.

Anderson, M. E. and Bluhm, H.: Description of a new species of Pachycara Zugmayer, 1911 from the abyssal south-eastern Pacific and redescription of P. thermophilum Geistdoerfer, 1994, with a new key to the species, T. Roy. Soc. S. Afr., 51, 219-227, 1997.

Bailey, D. M., King, N. J., and Priede, I. G.: Cameras and carcasses: historical and current methods for using artificial food falls to study deep-water animals, Mar. Ecol.-Prog. Ser., 350, 179-191, 2007.

Bluhm, H.: Monitoring megabenthic communities in abyssal manganese nodule sites of the East Pacific Ocean in association with commercial deep-sea mining, Aquat. Conserv., 4, 187-201, https://doi.org/10.1002/aqc.3270040302, 1994.

Bluhm, H.: Re-establishment of an abyssal megabenthic community after experimental physical disturbance of the seafloor, DeepSea Res. Pt. II, 48, 3841-3868, https://doi.org/10.1016/S09670645(01)00070-4, 2001.

Bluhm, H., Schriever, G., and Thiel, H.: Megabenthic recolonization in an experimentally disturbed abyssal manganese nodule area, Mar. Georesour. Geotec., 13, 393-416, https://doi.org/10.1080/10641199509388295, 1995.

Bonito, L. T., Hamdoun, A., and Sandin, S. A.: Evaluation of the global impacts of mitigation on persistent, bioaccumulative and toxic pollutants in marine fish, PeerJ, 4, e1573, https://doi.org/10.7717/peerj.1573, 2016.
Borowski, C.: Physically disturbed deep-sea macrofauna in the Peru Basin, southeast Pacific, revisited 7 years after the experimental impact, Deep-Sea Res. Pt. II, 48, 3809-3839, https://doi.org/10.1016/S0967-0645(01)00069-8, 2001.

Brandt, A., Malyutina, M., Borowski, C., Schriever, G., and Thiel, H.: Munnopsidid isopod attracted to bait in the DISCOL area, Pacific Ocean, Mitt. hamb. Zool. Mus. Inst., 101, 275-279, 2004.

Chouvelon, T., Spitz, J., Caurant, F., Mendez-Fernandez, P., Autier, J., Lassus-Debat, A., Chappuis, A., and Bustamante, P.: Enhanced bioaccumulation of mercury in deep-sea fauna from the Bay of Biscay (north-east Atlantic) in relation to trophic positions identified by analysis of carbon and nitrogen stable isotopes, Deep-Sea Res. Pt. 1, 65, 113-124, 2012.

Choy, C. A., Popp, B. N., Kaneko, J. J., and Drazen, J. C.: The influence of depth on mercury levels in pelagic fishes and their prey, P. Natl. Acad. Sci. USA, 106, 13865-13869, 2009.

Colton, M. A. and Swearer, S. E.: A comparison of two survey methods: differences between underwater visual census and baited remote underwater video, Mar. Ecol.-Prog. Ser., 400, 1936, https://doi.org/10.3354/meps08377, 2010.

Crabtree, R. E., Carter, J., and Musick, J. A.: The comparative feeding ecology of temperate and tropical deep-sea fishes from the western North Atlantic, Deep Sea Res., 38, 1277-1298, 1991.

Doya, C., Chatzievangelou, D., Bahamon, N., Purser, A., De Leo, F. C., Juniper, S. K., Thomsen, L., and Aguzzi, J.: Seasonal monitoring of deep-sea megabenthos in Barkley Canyon cold seep by internet operated vehicle (IOV), PLOS ONE, 12, e0176917, https://doi.org/10.1371/journal.pone.0176917, 2017.

Drazen, J. C. and Sutton, T. T.: Dining in the deep: The feeding ecology of deep-sea fishes, Annu. Rev. Mar. Sci., 9, 337-366, https://doi.org/10.1146/annurev-marine-010816-060543, 2017.

Estes, J. A., Terborgh, J., Brashares, J. S., Power, M. E., Berger, J., Bond, W. J., Carpenter, S. R., Essington, T. E., Holt, R. D., Jackson, J. B. C., Marquis, R. J., Oksanen, L., Oksanen, T., Paine, R. T., Pikitch, E. K., Ripple, W. J., Sandin, S. A., Scheffer, M., Schoener, T. W., Shurin, J. B., Sinclair, A. R. E., Soulé, M. E., Virtanen, R., and Wardle, D. A.: Trophic downgrading of planet Earth, Science, 333, 301-306, https://doi.org/10.1126/science.1205106, 2011.

Fleury, A. G. and Drazen, J. C.: Abyssal scavenging communities attracted to sargassum and fish in the Sargasso sea, Deep-Sea Res. Pt. I, 72, 141-147, https://doi.org/10.1016/j.dsr.2012.11.004, 2013.

Foell, E. J., Schriever, G., Bluhm, H., Borowski, C., Bussau, C., and Thiel, H.: Disturbance and Recolonization Experiment in the Abyssal South Pacific Ocean (DISCOL): An Update, 24th annual Offshore Technology Conference, Houston, Texas, 6805, 25-34, https://doi.org/10.4043/6805-MS, 1992.

Gollner, S., Kaiser, S., Menzel, L., Jones, D. O. B., Brown, A., Mestre, N. C., van Oevelen, D., Menot, L., Colaço, A., Canals, M., Cuvelier, D., Durden, J. M., Gebruk, A., Egho, G. A., Haeckel, M., Marcon, Y., Mevenkamp, L., Morato, T., Pham, C. K., Purser, A., Sanchez-Vidal, A., Vanreusel, A., Vink, A., and Martinez Arbizu, P.: Resilience of benthic deep-sea fauna to mining activities, Mar. Environ. Res., 129, 76-101, https://doi.org/10.1016/j.marenvres.2017.04.010, 2017.

Jones, D. O. B., Kaiser, S., Sweetman, A. K., Smith, C. R., Menot, L., Vink, A., Trueblood, D., Greinert, J., Billett, D. S. M., Arbizu, P. M., Radziejewska, T., Singh, R., Ingole, B., 
Stratmann, T., Simon-Lledó, E., Durden, J. M., and Clark, M. R.: Biological responses to disturbance from simulated deepsea polymetallic nodule mining, PLOS ONE, 12, e0171750, https://doi.org/10.1371/journal.pone.0171750, 2017.

Jones, D. O. B., Amon, D. J., and Chapman, A. S. A.: Mining deepocean mineral deposits: What are the ecological risks?, Elements, 14, 325-330, https://doi.org/10.2138/gselements.14.5.325, 2018.

Kuhnz, L. A., Ruhl, H. A., Huffard, C. A., and Smith, K. L.: Rapid changes and long-term cycles in the benthic megafaunal community observed over 24 years in the abyssal northeast Pacific, Prog. Oceanogr., 543, 1-11, 2014.

Leitner, A. B., Neuheimer, A. B., Donlon, E., Smith, C. R., and Drazen, J. C.: Environmental and bathymetric influences on abyssal bait-attending communities of the Clarion Clipperton Zone, Deep-Sea Res. Pt. I, 125, 65-80, https://doi.org/10.1016/j.dsr.2017.04.017, 2017.

Levin, L. A., Mengerink, K., Gjerde, K. M., Rowden, A. A., Van Dover, C. L., Clark, M. R., Ramirez-Llodra, E., Currie, B., Smith, C. R., Sato, K. N., Gallo, N., Sweetman, A. K., Lily, H., Armstrong, C. W., and Brider, J.: Defining "serious harm" to the marine environment in the context of deep-seabed mining, Mar. Policy, 74, 245-259, https://doi.org/10.1016/j.marpol.2016.09.032, 2016.

Linley, T. D., Gerringer, M. E., Yancey, P. H., Drazen, J. C., Weinstock, C. L., and Jamieson, A. J.: Fishes of the hadal zone including new species, in situ observations and depth records of hadal snailfishes Deep-Sea Res. Pt. I, 114, 99-110, https://doi.org/10.1016/j.dsr.2016.05.003, 2016.

Linley, T. D., Stewart, A., McMillan, P., Clark, M., Gerringer, M., Drazen, J. C., Fujii, T., and Jamieson, A. J.: Bait attending fishes of the abyssal zone and hadal boundary: community structure, functional groups and species distribution in the Kermadec, New Hebrides and Mariana trenches, Deep-Sea Res. Pt. I, 121, 38-53, 2017

Marcon, Y. and Purser, A.: PAPARA(ZZ)I: An open-source software interface for annotating photographs of the deep-sea, SoftwareX, 6, 69-80, https://doi.org/10.1016/j.softx.2017.02.002, 2017.

Miljutin, D. M., Miljutin, M. A., Arbizu, P. M., and Galeron, J.: Deep-sea nematode assemblage has not recovered 26 years after experimental mining of polymetallic nodules (Clarion-Clipperton Fracture Zone, Tropical Eastern Pacific), Deep-Sea Res. Pt. I, 58, 885-897, https://doi.org/10.1016/j.dsr.2011.06.003, 2011.

Milligan, R. J., Morris, K. J., Bett, B. J., Durden, J. M., Jones, D. O. B., Robert, K., Ruhl, H. A., and Bailey, D. M.: High resolution study of the spatial distributions of abyssal fishes by autonomous underwater vehicle, Sci. Rep.-UK, 6, 26095, https://doi.org/10.1038/srep26095, 2016.

Nielsen, J. G.: Synopsis of the Ipnopidae (Pisces, Iniomi): with a description of two new abyssal species, Galathea Report, 8, 49$75,1966$.

Nielsen, J. G. and Merrett, N. R.: Revision of the cosmopolitan deep-sea genus Bassozetus (Pisces: Ophidiidae) with two new species, Galathea Report, 18, 7-56, 2000.

Oebius, H. U., Becker, H. J., Rolinski, S., and Jankowski, J. A.: Parametrization and evaluation of marine environmental impacts produced by deep-sea manganese nodule mining, Deep-
Sea Res. Pt. II, 48, 3453-3467, https://doi.org/10.1016/S09670645(01)00052-2, 2001.

Pawson, D. L. and Foell, E. J.: Atlas of Photographs of Megafauna from the Study Area. Report No. MS-200-146 of Deepsea Ventures Inc., Gloucester Point, Virginia, 120 pp., 1983.

Priede, I. G.: Deep-Sea Fishes: Biology, Diversity, Ecology and Fisheries, Cambridge University Press, Cambridge, 2017.

Priede, I. G. and Merrett, N. R.: The relationship between numbers of fish attracted to baited cameras and population density: Studies on demersal grenadiers Coryphaenoides (Nematonurus) armatus in the abyssal NE Atlantic Ocean, Fish. Res., 36, 133137, 1998.

Purser, A., Marcon, Y., Hoving, H.-J. T., Vecchione, M., Piatkowski, U., Eason, D., Bluhm, H., and Boetius, A.: Association of deep-sea incirrate octopods with manganese crusts and nodule fields in the Pacific Ocean, Curr. Biol., 26, R1268-R1269, https://doi.org/10.1016/j.cub.2016.10.052, 2017.

Purser, A., Marcon, Y., Dreutter, S., Hoge, U., Sablotny, B., Hehemann, L., Lemburg, J., Dorschel, B., Biebow, H., and Boetius, A.: Ocean Floor Observation and Bathymetry System (OFOBS): A new Towed Camera/Sonar System for Deep-Sea Habitat Surveys, IEEE J. Oceanic Eng., 44, 1-13, https://doi.org/10.1109/JOE.2018.2794095, 2018a.

Purser, A., Marcon, Y., and Boetius, A.: Seafloor images from the Peru Basin Disturbance and Colonization (DISCOL) area collected during SO242/2, Alfred Wegener Institute, Helmholtz Centre for Polar and Marine Research, Bremerhaven, PANGAEA, https://doi.org/10.1594/PANGAEA.890634, 2018b.

Purser, A., Langenkämper, D., Schoening, T., Suck, I., Taylor, J., Cuvelier, D., Lins, L., Simon-Lledo, E., Marcon, Y., Jones, D., Nattkemper, T., Koeser, K., Zurowietz, M., and Nuno Pereira, J.: Polymetallic nodule megafauna community assessment: Platform and methodology comparison, Biogeosciences Discuss., in preparation, 2019.

Radziejewska, T. and Stoyanova, S.: Abyssal epibenthic megafauna of the Clarion-Clipperton area (NE Pacific): Changes in time and space versus anthropogenic environmental disturbance, Oceanological Studies, 29, 83-101, 2000.

Ramirez-Llodra, E., Tyler, P. A., Baker, M. C., Bergstad, O. A., Clark, M. R., Escobar, E., Levin, L. A., Menot, L., Rowden, A. A., Smith, C. R., and Van Dover, C. L.: Man and the last great wilderness: Human impact on the deep sea, PLoS ONE, 6, e22588, https://doi.org/10.1371/journal.pone.0022588, 2011.

Rolinski, S., Segschneider, J., and Sündermann, J.: Long-term propagation of tailings from deep-sea mining under variable conditions by means of numerical simulations, Deep-Sea Res. Pt. II, 48, 3469-3485, https://doi.org/10.1016/S0967-0645(01)000534, 2001.

Ruhl, H. A. and Smith Jr., K. L.: Shifts in deep-sea community structure linked to climate and food supply, Science, 305, 513515, 2004.

Stratmann, T., Voorsmit, I., Gebruk, A., Brown, A., Purser, A., Marcon, Y., Sweetman, A. K., Jones, D. O. B., and van Oevelen, D.: Recovery of Holothuroidea population density, community composition, and respiration activity after a deep-sea disturbance experiment, Limnol. Oceanogr., 63, 2140-2153, https://doi.org/10.1002/lno.10929, 2018.

Thiel, H., Schriever, G., Ahnert, A., Bluhm, H., Borowski, C., and Vopel, K.: The large-scale environmental impact experi- 
ment DISCOL - reflection and foresight, Deep-Sea Res. Pt. II, 48, 3869-3882, https://doi.org/10.1016/S0967-0645(01)000716, 2001.

Tilot, V.: Biodiversity and distribution of megafauna. Vol. 1: The polymetallic nodule ecosystem of the Eastern Equatorial Pacific Ocean; Vol. 2: Annotated photographic atlas of the echinoderms of the Clarion-Clipperton fracture zone, UNESCO IOC Technical Series69, 147 pp., 2006.

Trenkel, V. M., Lorance, P., and Mahevas, S.: Do visual transects provide true population density estimates for deepwater fish?, ICES J. Mar. Sci., 61, 1050-1056, 2004.

Vanreusel, A., Hilario, A., Ribeiro, P. A., Menot, L., and Arbizu, P. M.: Threatened by mining, polymetallic nodules are required to preserve abyssal epifauna, Sci. Rep.-UK, 6, 26808, https://doi.org/10.1038/srep26808, 2016.

Watling, L., Guinotte, J., Clark, M. R., and Smith, C. R.: A proposed biogeography of the deep ocean floor, Prog. Oceanogr., 111, 91112, https://doi.org/10.1016/j.pocean.2012.11.003, 2013.
Wedding, L. M., Friedlander, A. M., Kittinger, J. N., Watling, L., Gaines, S. D., Bennett, M., Hardy, S. M., and Smith, C. R.: From principles to practice: a spatial approach to systematic conservation planning in the deep sea, P. Roy. Soc. B-Biol., 280, 20131684, https://doi.org/10.1098/rspb.2013.1684, 2013.

Wedding, L. M., Reiter, S. M., Smith, C. R., Gjerde, K. M., Kittinger, J. N., Friedlander, A. M., Gaines, S. D., Clark, M. R., Thurnherr, A. M., Hardy, S. M., and Crowder, L. B.: Managing mining of the deep seabed, Science, 349, 144-145, https://doi.org/10.1126/science.aac6647, 2015.

Yeh, J. and Drazen, J. C.: Depth zonation and bathymetric trends of deep-sea megafaunal scavengers of the Hawaiian Islands, DeepSea Res. Pt. I, 56, 251-266, 2009.

Yeh, J. and Drazen, J. C.: Baited-camera observations of deepsea megafaunal scavenger ecology on the California slope, Mar. Ecol.-Prog. Ser., 424, 145-156, 2011. 